\title{
Pain following spinal cord injury
}

\author{
Gülçin Demirel, Hürriyet Yllmaz, Belgin Gençosmanoğlu and Nur Kesiktaş \\ Istanbul Physical Medicine and Rehabilitation Centre, Istanbul, Turkey
}

\begin{abstract}
Some patients with spinal cord injury (SCI) complain of severe pain. The purpose of this study was to investigate the prevalence and classification of SCI-related pain, in terms of severity, location, aggravating and alleviating factors. 47 SCI individuals were studied between 15 and 67 years of age. Sixty-one percent of subjects experienced pain of moderate to severe intensity. 32 subjects complained of pain in the lower limbs, five patients had pain in the visceral region, eight in the pelvic and perineal areas. The pain duration was for a median of 5 weeks. The patients with pain were older (median 41 years) than those without pain (median 23 years). Pain was reported to be more intense in the evening and at night. The incidence of pain was higher in patients with thoracolumbar and incomplete spinal cord lesions. Inactivity, stress, weather change, overactivity were identified as aggravating factors. Sleep and rest were demonstrated as alleviating factors.
\end{abstract}

Keywords: spinal cord injuries; pain

\section{Introduction}

Spinal cord injury (SCI) often presents with a secondary pain syndrome. Estimates of prevalence rates for chronic pain in SCI range from $48-94 \%$, and from $18-63 \%$ for severe pain. ${ }^{1-8}$ Although loss of function is often considered to be the most significant consequence of SCI, pain itself has a direct bearing on the ability or inability of the spinal cord injured person to regain his or her optimal level of activity. ${ }^{9}$

Many of these studies are limited by a lack of discrimination between pain syndrome types. A number of categories and descriptions of SCI pain have been reported. ${ }^{6,7,9,10}$

The purpose of this study was to investigate the prevalence and classification of SCI related pain, in terms of severity, location, aggravating and alleviating factors.

\section{Methods}

The study includes 47 patients suffering from SCI, who were treated in the Istanbul Physical Medicine and Rehabilitation Centre. Neurological examinations were performed in all patients. No patient received drugs which could affect pain. Determinations of the motor and sensory injury levels and the completeness of the injury were made according to the American Spinal Injury Association criteria. ${ }^{11}$ In this study pain is evaluated in terms of severity, types, location and aggravating and alleviating factors. Pain severity

Correspondence: G Demirel during the last week was rated by the patients on a six point scale (none, slight, moderate, severe, very severe and unbearable pain). Our studies were based upon the following description of different types of pain in spinal cord injured patients by Christensen and Jensen. ${ }^{12}$ The patients with pain were classified into five categories: diffuse pain, segmental pain, root pain, visceral pain and non neurogenic pain. Diffuse pain; multifarious, characterized by constant, diffuse, generalized, burning, pricking, tingling pain in paralysed and anaesthetic areas. Segmental pain; often bilateral symmetric occurrence within two or three spinal segments of the zone of injury, spontaneous, burning character, hyperalgesic border reaction. Root pain; asymetric, segmental localized pain, sharp, with paroxysmal occurrence. Visceral pain can be identified by location (abdomen) and pain features (dull, poorly localised, cramping, related to visceral function or pathology). Non neurogenic pain; such as musculoske-

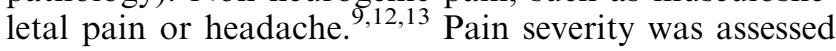
on a visual analog scale (VAS) three times daily for 7 days.

For comparisons of groups of data simple crosstabulation was performed (Fisher's exact test), while the Mann-Whitney nonparametric two sample test was used to analyse differences in medians; we considered $P$ values $<0.05$ statistically significant.

\section{Results}

This study sample included 29 men and 18 women between the ages of 15 and 67 years (mean $31.40 \pm 10.65)$. The levels of spinal injury were 
distributed as follows: C1-C7 (23\%), T2-T6 (14\%), T7-L2 (59\%) and below L2 (4\%). The average duration of SCI was 18 weeks (range 8-120 weeks). Table 1 shows the completeness and the level of injury and the time from injury and etiology. Most of the patients were paraplegic or had incomplete injuries, and a traffic accident was the most frequent etiology.

Sixty-one percent of the subjects experienced pain of moderate to severe intensity. The patients with pain rated their subjective experience of pain intensity three times daily on a visual analog scale. Pain was reported to be more intense in the evening (Figure 1).

In our study, this main classification gave five categories (Figure 2). All of the patients reported pain at or below the level of the lesion at some time since the injury. Most of the subjects (32) complained of

Table 1 Level and completeness of injury, time from injury, and etiology

\begin{tabular}{lcc}
\hline Paraplegic (77\%) & Incomplete & $53 \%$ \\
& Complete & $24 \%$ \\
Quadriplegic (23\%) & Incomplete & $15 \%$ \\
& Complete & $8 \%$ \\
Etiology & & $51 \%$ \\
& Traffic accident & $24 \%$ \\
& Fall & $11 \%$ \\
& Gunshot & $10 \%$ \\
& Diving-Water sports & $4 \%$ \\
\hline
\end{tabular}

pain in the lower limbs, five patients had pain in the visceral region, eight in the pelvic and perineal areas.

The patients with pain were older (median 41 years) than those without pain (median 23 years) $(P<0.05)$. No differences between men and women groups were found for presence of pain $(18$ men $-62.06 \%$ versus 11 women $-61.11 \%, P>0.05)$. Subjects were divided into traffic accident and non traffic accident groups. No differences between groups were found for pain intensity ratings.

Two patients experienced immediate onset of pain after the injury. Seven patients developed pain within 1 month following injury. The pain was initiated after 3 months following injury in eight subjects and 12 patients developed pain after 6 months following injury. Time since injury was not statistically significant between groups with and without pain. The pain duration was more common with thoracolumbar lesions than with cervical lesions. The incidence of pain was greater in patients with incomplete lesions (Figure 3).

Spasticity, inactivity, overexertion, stress, weather changes were frequently identified as aggravating factors. Rest and sleep were cited as alleviating factors.

\section{Discussion}

Chronic pain is a common clinical finding in people who have had a spinal cord injury. ${ }^{6,7,14}$ The prevalence of pain in the present study $(61 \%)$ is comparable with the findings of Woolsey $(67 \%),{ }^{15}$ Rose $(69 \%)^{16}$ and

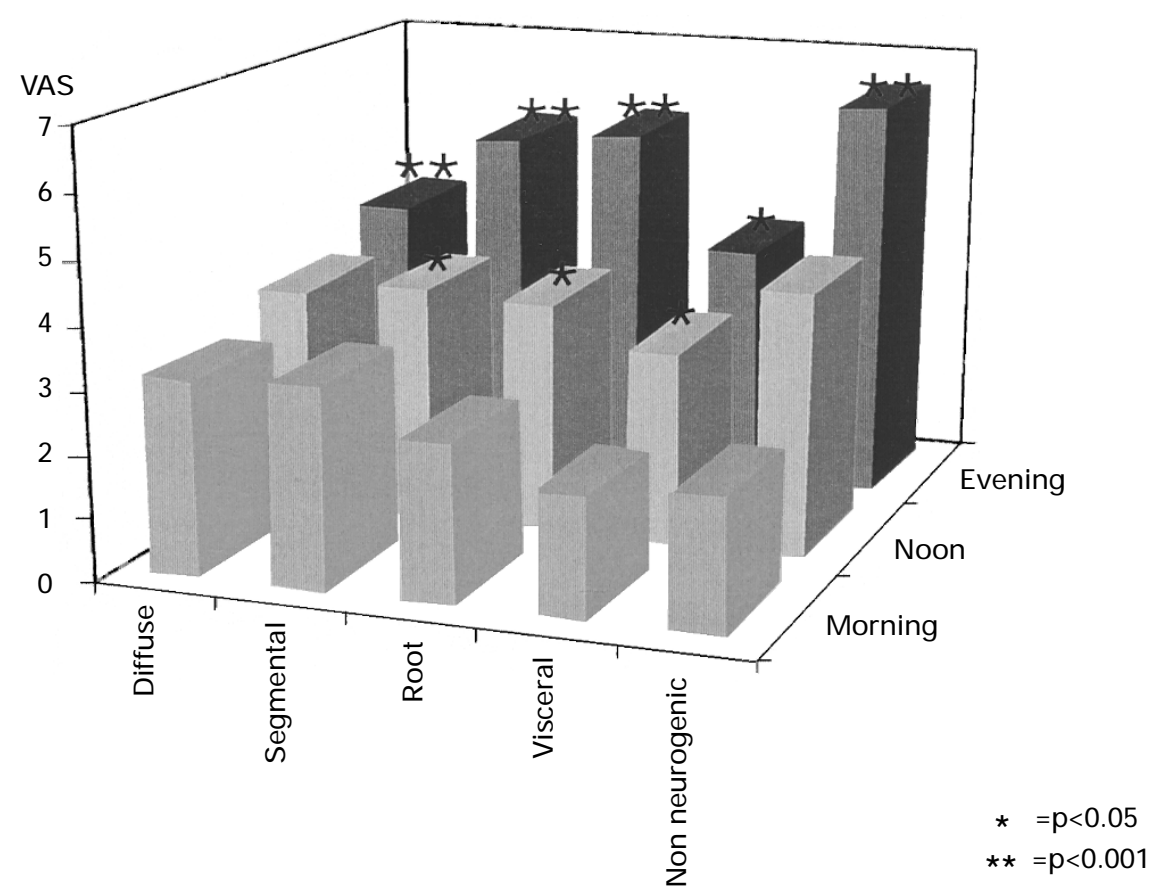

Figure 1 Pain intensity rated three times daily in patients 


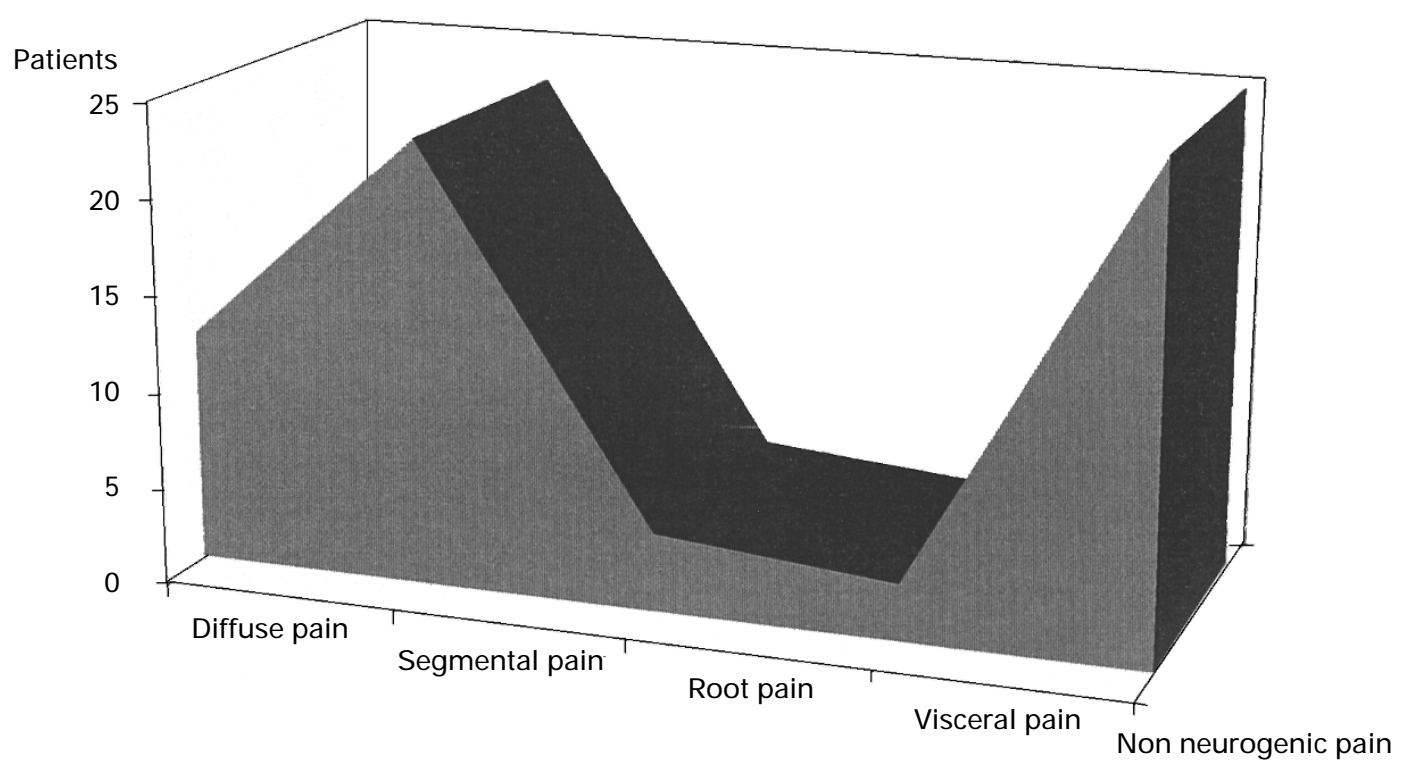

Figure 2 Prevalence of pain in patients

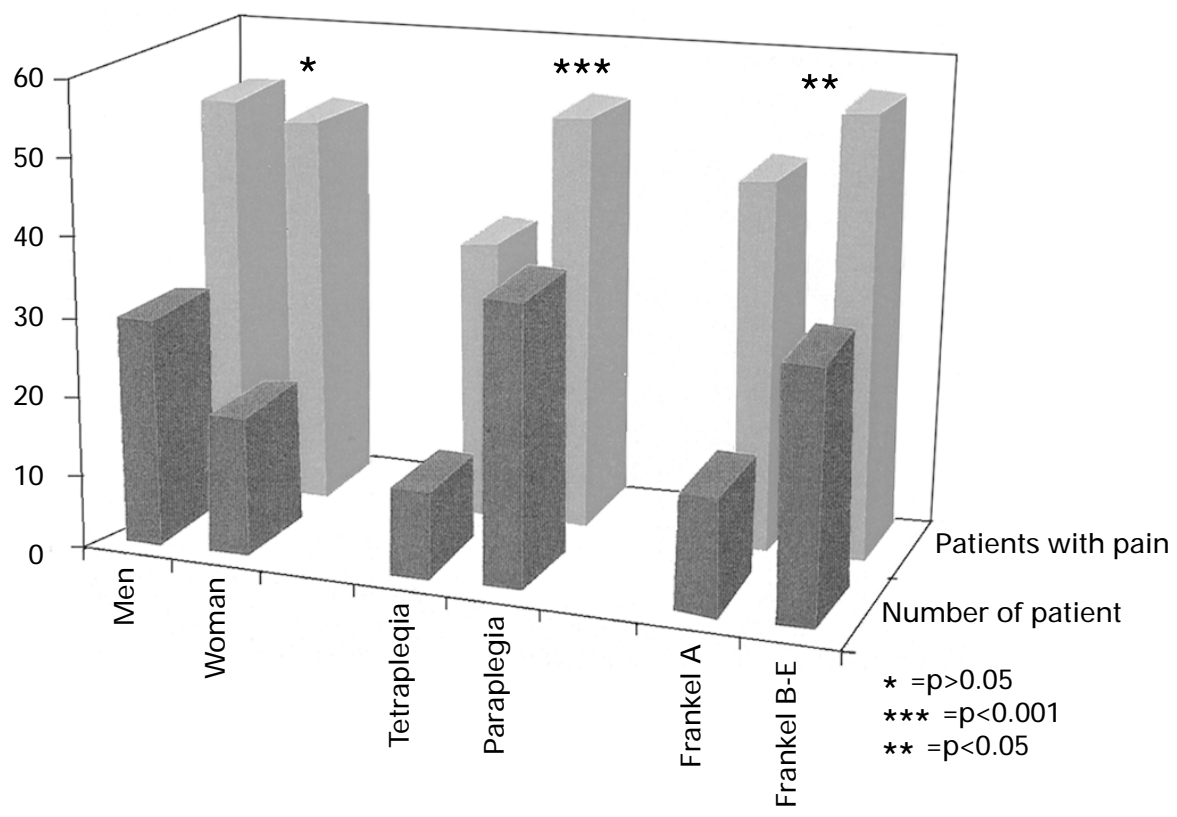

Figure 3 The relation between pain and sex, spinal cord lesion level, Frankel classification

Lamid $(60 \%),{ }^{7}$ but higher than the prevalence reported by Wagner $(45 \%)^{17}$ or Britell $(42 \%){ }^{10}$ These discrepancies can be explained by the definitions of pain, as our studies also included patients who had mild pain.

To our knowledge, there is no previous report on the increased prevalence of pain in patients who were injured at a higher age compared with the prevalence in those who were injured at younger age. ${ }^{17,18}$ No association was found between patient's age and prevalence of pain in a previous report. ${ }^{19}$ In this study the group with pain was significantly older (41 years) than the patients without pain (23 years).

Some authors have claimed diffuse pain to be most frequent after spinal cord injury. $5,10,16$ Other authors found that segmental pain was the most common pain type. ${ }^{17}$ We have found that diffuse pain was the most frequent pain type.

In contrast to our study, Mariano, ${ }^{5}$ Douglas, ${ }^{8}$ Summers, ${ }^{14}$ Wagner, ${ }^{17}$ Subbarao ${ }^{19}$ demonstrated no association between the presence of pain, its severity and the level or the completeness of injury. Our results 
were in accordance with Nepomuceno ${ }^{20}$ and Davidoff, ${ }^{21}$ who found an increased risk of pain in paraplegic versus tetraplegic patients, and in patients with incomplete versus those with complete spinal cord lesions.

Subbarao et al found no association between the time since injury and pain, ${ }^{19}$ and in our study, time from injury was not significant in patients with pain. Our results demonstrated that pain was more intense in the evening and night than in the morning. This result is important in the management of pain. In a previous report activity, inactivity, weather change and overexertion were not found to be aggravating factors. ${ }^{20} \mathrm{We}$ found that inactivity, overexertion, stress, weather change were important aggravating factors for pain. Rest and sleep may decrease pain by providing relaxation.

In conclusion, pain evaluation is an important component of SCI rehabilitation. The intensity and location of pain must be considered when determining rehabilitation goals and treatment.

\section{References}

1 Cohen et al. Comparing chronic pain from spinal cord injury to chronic pain of other origins. Pain 1988; 35: 57-63.

2 Frisbie JH, Aquilera EJ. Chronic pain after spinal cord injury: an expedient diagnostic approach. Paraplegia 1990; 28: 460 - 465.

3 Bonica JJ. Introduction: sementic, epidemiologic, and educational issues. In: Casey KL (ed). Pain and Central Nervous System Disease: The Central Pain Syndromes. Raven Press: New York, 1991, pp 13-29.

4 Wegener ST, Elliot TR. Pain assessment in Spinal cord injury. Clin J Pain 1992; 8: $93-101$.

5 Mariano AJ. Chronic pain and spinal cord injury. Clin J Pain 1992; 8: $87-92$.
6 Richards JS. Chronic pain and spinal cord injury: review and comment. Clin J Pain 1992; 8: 119-122.

7 Lamid S, Chia JK, Kohl A, Cid E. Chronic pain in spinal cord injury; comparison between inpatients and outpatients. Arch Phys Med Rehabil 1985; 66: $777-778$.

8 Douglas MC, Rodney HA, Michael DS. Pain and depression in acute traumatic spinal cord injury: Origins of chronic problematic pain? Arch Phys Med Rehabil 1996; 77: 329-335.

9 Siddall PJ, Taylor DA, Cousins MJ. Classification of pain following spinal cord injury. Spinal Cord 1997; 35: 69-75.

10 Britell CW, Mariano AJ. Chronic pain in spinal cord injury. Phys Med Rehabil 1991; 5: 71-82.

11 Ditunno JF, Young W, Donovan WH, Creasey G. The International Standards Booklet for Neurological and Functional Classification of Spinal Cord Injury. Paraplegia 1994; 32: $70-80$.

12 Christensen FL, Jensen TS. Disturbances of sensation and pain in patients with spinal cord lesions (Danish). Ugeskr Loeger 1991; 153: $3466-3469$

13 Bonica JJ. General considerations of chronic pain. In: Bonica JJ (ed). The management of pain. Philadelphia: Lea \& Febiger; 1990: 180196.

14 Summers JD et al. Psychosocial factors in chronic spinal cord injury pain. Pain 1991; 42: $181-189$.

15 Woolsey RM. Chronic pain following spinal cord injury. $J$ Am Paraplegia Soc 1986; 9: 39-41.

16 Rose M, Robinson JE, Ellis P, Cole JD. Pain following spinal cord injury: results from a postal survey. Pain 1988; 34: 101-102.

17 Wagner Anke AG, Stenehjem AE, Kvalvik Stanghelle J. Pain and life quality within 2 years of spinal cord injury. Paraplegia 1995; 33: $555-569$.

18 Richards JS et al. Psychosocial aspects of chronic pain in spinal cord injury. Pain 1980; 8: 355-366.

19 Subbarao JU, Klopfstein J, Turpin R. Prevalence and impact of wrist and shoulder pains in patients with spinal cord injury. $J$ Spinal Cord Med 1995; 18: 9-13.

20 Nepomuceno $\mathrm{C}$ et al. Pain in patients with spinal cord injury. Arch Phys Med Rehabil 1979; 60: 605-609.

21 Davidoff $\mathrm{G}$ et al. Function limiting dysaesthetic pain syndrome among traumatic spinal cord injury patients: a cross sectional study. Pain 1987; 29: $39-48$. 